\title{
PERFIL DAS CRIANÇAS E ADOLESCENTES VÍTIMAS DE VIOLÊNCIA SEXUAL EM FEIRA DE SANTANA
}

\author{
$\underline{\text { Anna Carolina Rocha da Silva }}{ }^{\mathbf{1}}$; Maria Conceição Oliveira Costa ${ }^{2}$
}

\author{
1. Bolsista PIBIC/CNPq, Universidade Estadual de Feira de \\ Santana, Graduando em Farmácia, e-mail: annacarolinarocha@ hotmail.com.br \\ 2. Orientador, Universidade Estadual de Feira de \\ Santana, Departamento de Saúde, e-mail: oliveiramco69@gmail.com
}

PALAVRAS-CHAVE: Violência infanto-juvenil; Sistema de segurança pública; Garantia de direitos

\section{INTRODUÇÃO}

A violência apresenta-se como um fenômeno mundial, sendo evidenciada nos mais distintos contextos culturais e sócio-econômicos. Segundo o Ministério da Saúde, a violência representa uma das principais causas de morbimortalidade no país, sobretudo entre a população jovem (BRASIL, 2005). Existem diversas formas de manifestação da violência e dentre elas, o destaque desse estudo é a violência sexual que se configura como uma agressão ainda mais complexa que as demais, pois além de comprometer a integridade física e psicológica da vítima, afeta a sua sexualidade (MONTEIRO et al., 2008). A violência sexual contra crianças e adolescentes que antes era vista como limitada ao campo social e jurídico, hoje é reconhecida como uma questão de saúde pública, já que representa agravo e ameaça à vida, às condições de trabalho, às relações interpessoais, e à qualidade da existência, tornando necessária a incorporação de uma atitude de responsabilização por parte dos profissionais de saúde (MINAYO; SOUZA, 1999). Crianças e adolescentes vítimas de violência sexual apresentam uma predisposição a apresentarem transtorno de ansiedade, depressão e quadros agressivos, bem como dificuldades de definir o seu papel e funcionamento sexual além de dificuldades com relacionamentos interpessoais (SERAFIM, 2011). O interesse na realização desse estudo originou-se devido à experiência como voluntária do Núcleo de Estudos e Pesquisas na Infância e Adolescência, no qual houve a oportunidade de conhecer e explorar essa temática. Além dessa experiência acadêmica, na condição de estudante da área de saúde, há também uma grande afinidade pela área de saúde da criança e do adolescente, bem como um compromisso social e profissional em busca de uma melhoria na qualidade de vida infanto-juvenil. Esse estudo contribuirá fornecendo dados que possibilitarão o desenvolvimento de ações voltadas para a prevenção e enfrentamento da violência e elaboração de políticas públicas, através da combinação entre os diferentes setores envolvidos, permitindo então que as crianças e adolescentes completem seu desenvolvimento de forma saudável e digna.

\section{METODOLOGIA}

Tipo do estudo: Estudo epidemiológico descritivo, de corte transversal, com base em dados secundários dos Boletins de Ocorrência das Delegacias Especializadas. Local de estudo: município de Feira de Santana, segunda maior cidade do Estado da Bahia/Brasil, e cortada por três Rodovias Federais (BR 101, 116 e 324) e cinco Rodovias Estaduais (BA 052, 068, 501, 502 e 503), sendo considerado um dos importantes entroncamentos rodoviários do Norte e Nordeste do Brasil (IBGE, 2000). População, Amostra e Período de referência: A população do presente estudo foi constituída por crianças e adolescentes vítimas de agressões sexuais notificadas à autoridade policial na Delegacia de Polícia Civil, DEAM, DERCA e DAÍ, do 
município de Feira de Santana, no período de 2005 a 2010. Instituições estudadas: Delegacia de Repressão ao Crime Contra a Criança e o Adolescente - DERCA: onde são encaminhadas todas as queixas e denúncias de violência contra crianças e adolescentes. Delegacia do Adolescente Infrator - DAÍ: órgão destinado a receber denúncias de vítimas e suspeitos; lavrar auto de apreensão ou boletim de ocorrência; instaurar inquéritos para apurar os fatos e encaminhar relatório ao Ministério público. Delegacia Especializada de atendimento à Mulher - DEAM: unidade especializada da Polícia Civil direcionada ao atendimento à mulher em situação de violência de gênero. Delegacia de Polícia Civil: representa uma unidade policial fixa dirigida por um Delegado de Polícia Civil e direcionada para o atendimento ao público (população), base e administração de operações policiais, investigações criminais e detenção temporária de suspeitos e presos em flagrante delito. Coleta de dados: Os dados foram coletados em formulário específico a partir dos registros originais de denúncia das Delegacias Especializadas (Boletins de Ocorrência). As variáveis analisadas foram: 1. Característica da vitimização e da vítima (sexo da vítima, faixa etária da vítima, tipo de violência, local de ocorrência, contexto do abuso, manifestação do abuso, forma de manifestação - com ou sem contato físico, presença de agressão física e tipo de intimidação) e características sociodemográficas e comportamental dos agressores sexuais de crianças e adolescentes (sexo do agressor, faixa etária do agressor, situação conjugal, se trabalha ou não, se possui histórico de detenção e vínculo com a vítima).

Análise de Dados: Os dados foram analisados com o auxílio do programa estatístico Statistical Package for Social Sciences - SPSS, versão 10.0.

\section{RESULTADOS E DISCUSSÃO}

No que diz respeito ao perfil das vítimas de agressão sexual, os dados encontrados nessa pesquisa corroboram com os estudos de Martins e Jorge Mello (2010), em que aponta-se que houve predomínio de vítimas do sexo feminino para agressão sexual, o que representa uma desigualdade de gênero ainda existente na sociedade, que em nível mundial, é um fenômeno social marcado por relações de poder e dominação, do masculino sobre o feminino. A faixa etária predominante foi dos 10 aos 14 anos, idade em que a vítima já entra na puberdade e começa a passar por mudanças fisiológicas, passando também a despertar maior atração de agressores, bem como, se encontra em uma idade em que o agressor possui a capacidade de seduzir a vítima financeiramente, tornando-a dependente, o que entra em concordância com os resultados encontrados para agressores que trabalham e não utilizam de força física para abusar da vítima, optando pela sedução da mesma, tanto psicológica quanto financeira. Portanto, por agirem de maneira silenciosa e sem utilização de agressão física, esse tipo de violência acabando permanecendo oculta diante da família da vítima e dos profissionais responsáveis por dar encaminhamento às denúncias, o que explica o fato de os agressores não possuírem históricos de detenção. Desta forma, é necessário destinar uma maior atenção à esses casos, em que a violação é perpetrada por pessoa próxima, já que poderá acarretar consequências no desenvolvimento psíquico-emocional das vítimas e no estabelicmento das relações sociais durante o seu crescimento pessoal. Ainda com relação aos agressores sexuais das crianças e adolescentes, os dados apontaram para uma maioria de idade de 25 à 49 anos, que por serem agressores adultos, presume-se que o estímulo pode estar ligadas à oportunidade encontrada e a vulnerabilidade etária da vítima (APA, 2002). Com relação à tipologia da violação, estudos de Vasconcelos (2010) apontam para uma maior freqüência de casos ocorrendo com abuso sexual, bem como foi constatado na presente pesquisa e Guimarães e Villela (2011) afirmam que a prevalência das ocorrências foram em ambiente doméstico e com contexto foi extrafamiliar. Portanto, pode-se concluir diante destes dados que provavelmente, indivíduos sem vínculo parentesco com a vítima tenham livre acesso ao interior da casa da vítima, 
possuindo até mesmo confiança tanto da vítima quanto dos seus cuidadores, dificultando ainda mais a possibilidade de se efetuar a denúncia e fazendo com que o abuso continue ocorrendo de maneira oculta. Porém, existem também outros estudos, como o de Martins e Jorge Mello (2010), que divergem destes dados, já que relatam maior incidência de abuso sexual ocorrendo dentro do próprio ambiente familiar. Contudo, para as duas situações, diante da violência, a vitima se torna omissa por medo de revelar o acontecimento da violência, já que a mesma possui receios, como ser acusado de provocar a violência por parte do agressor e por consequência disso sofrer humilhação ou afrontas, bem como incompreensão por parte dos familiares, amigos, vizinhos. Para os casos mais recorrentes, encontrados no presente estudo, que é a vitimização de adolescentes, ressalta-se a presença de atitudes preconceituosas, pela família, amigos e autoridades, com acusação da vítima, em ter favorecido ou provocado a violência, já que essa questão ainda envolve tabus e discriminação das vítimas como culpadas, o que colabora com a perpetuação da violência e que pode ser explicado pela falta de estrutura psicológica da vítima para comunicar o fato (KELLOG, 2002).

\section{CONSIDERAÇÕES FINAIS}

Diante dos dados encontrados, conclui-se que a maioria das vítimas de agressão sexual durante a fase da infância e adolescência encontram-se entre as idades de 10 à 14 anos, que é o estágio de transição entre essas duas fases. O sexo feminino ainda carrega consigo uma desigualdade de gênero, visto que a maioria das vitimas são meninas que estão entrando na puberdade. A partir deste estudo, nota-se também a necessidade uma maior atenção a ser dada a este assunto, não apenas pelos profissionais responsáveis pelos encaminhamentos das denúncias, mas também verifica-se a importância de políticas públicas destinadas à inserior uma abordagem nas comunidades, gerando a coscientização por parte dos familiares e pessoas próximas a vítima do quão oculta, comum e perigosa pode ser esse tipo de violência ocorrência dentro do próprio ambiente doméstico da vítima.

\section{REFERÊNCIAS}

Associação Psiquiátrica Americana (APA). Manual diagnóstico e estatístico de transtornos mentais. 4. ed. Porto Alegre: ArtMed; 2002.

BRASIL. Ministério da Saúde. Secretaria de Atenção à Saúde. Departamento de Ações Programáticas Estratégicas. Área Técnica de Saúde da Mulher. Prevenção e tratamento dos agravos resultantes da violência sexual contra mulheres e adolescentes. Norma Técnica. $2^{a}$ ed. Brasília: Ministério da Saúde, 2005.

GUIMARÃES, J. A. T. L.; VILELLA, W. V. Características da violência física e sexual contra crianças e adolescentes atendidos no IML de Maceió, Alagoas, Brasil. Cad. Saúde Pública. Rio de Janeiro, v. 27, n. 8, p. 1647-1653, 2011.

KELLOGG, N. D. Child sexual abuse: a marker or magnifying glass for family dysfunction? Int Soc Sci J. v.39, p. 569-82, 2002.

MARTINS, Christine Baccarat de Godoy; JORGE, Maria Helena Prado de Mello. Abuso sexual na infância e adolescência: perfil das vítimas e agressores em município do Sul do Brasil. Texto Contexto Enferm, Florianópolis, v.19, n. 2, p. 246-55, 2010. 
MONTEIRO, Claudete Ferreira de Souza et al. Violência sexual contra criança no meio intrafamiliar atendidos no SAMVVIS, Teresina, PI. Revista Brasileira de Enfermagem, vol. 61, n. 4, 2008.

MINAYO, Maria Cecília de Souza e SOUZA, Edinilsa Ramos de. É possível prevenir a violência? Reflexões a partir do campo da saúde pública. Ciência \& Saúde Coletiva, v. 4, n. $1,1999$.

MIRANDA, M. I. F. et al. Violência sexual contra crianças e adolescentes em um município da Região Norte do Brasil. Rev. Soc. Bras. Enferm. Ped. v. 14, n. 2, 2014.

SERAFIM, A. P. Dados demográficos, psicológicos e comportamentais de crianças e adolescentes vítimas de abuso sexual. Rev Psiq Clín. v. 38, n. 4, p.143-147, 2011.

VASCONCELOS, M. G. O. M.; FIGARO-GARCIA, C. Violência sexual infanto-juvenil: da Teoria à Prática do Centro de Referência e Atenção à Infância e Adolescência. In: LIBORIO, R. M. C.; SOUSA, S. M. G. (Org.). A exploração sexual de crianças e adolescentes no Brasil. Reflexões teóricas, relatos de pesquisa e intervenções psicossociais. $2^{\mathrm{a}}$ ed. São Paulo: Casa do Psicólogo; Goiânia: Universidade Católica de Goiás, 2007. p. 201-34. 